\title{
Editorial
}

\section{Cuidados Paliativos en el Primer Nivel de Atención}

\author{
Palliative Care in Primary Care Level \\ Cuidados paliativos em atenção primária
}

Mariana Navarro-Hernández*

La Organización Mundial de la Salud (oms) ha manifestado que un país puede considerar su sistema de salud como universal solamente cuando incluye en él los cuidados paliativos. La oms los define como el "cuidado total activo e integral, cuyo enfoque es el de mejorar la calidad de vida de los pacientes y familias que enfrentan los problemas asociados a enfermedades amenazantes para la vida, a través de la prevención y el alivio del sufrimiento por medio de la identificación temprana e impecable evaluación y tratamiento del dolor y otros problemas físicos, psicológicos, sociales y espirituales." Esta misma institución hace un llamado para que cada país incluya los cuidados paliativos en sus sistemas de salud, asumiendo el reto de encontrar la mejor manera de implementar y financiar los servicios asistenciales para cubrir la demanda existente y futura. La atención desde el primer nivel es posiblemente la clave para lograr su cobertura.

En México mueren al año 377 mil personas por enfermedades crónicodegenerativas, en ese contexto, el número de pacientes susceptibles a atención paliativa ascendería a 226 mil. La tendencia marca una disminución en las tasas de mortalidad, un mayor número de supervivientes con enfermedades crónico-degenerativas y por lo tanto, aumento en la esperanza de vida, condiciones que se estiman irán en la misma línea durante los siguientes años. Ante los inminentes cambios poblacionales, es urgente crear infraestructura y formar recursos humanos para atender a esta población y fortalecer el sistema de salud.

Actualmente existen diferentes modelos de atención en cuidados paliativos que pueden cubrir satisfactoriamente las necesidades del paciente, elegir el indicado dependerá del tipo de paciente, la enfermedad que se padezca, la etapa por la que cursa, así como del personal disponible y de la infraestructura con la que se cuente. Todos comparten una meta: mejorar la atención y calidad de vida del paciente y su familia, desde lo más básico, compuesto por medidas generales como movilidad, hidratación, sueño, alimentación e higiene, que pueden brindarse en cualquier servicio médico, hasta modelos más complejos, en los que expertos en cuidados paliativos atienden situaciones que requieren de recursos e infraestructura especializada. Una sola institución podría contar con varios modelos y un mismo paciente po-

Sugerencia de citación: Navarro-Hernández M. Cuidados Paliativos en el Primer Nivel de Atención. Aten Fam. 2017;24(3):95-96.
${ }^{*}$ Grupo de trabajo "Calidad al final de la vida", Seminario de Estudios sobre la Globalidad, Universidad Nacional Autónoma de México (UNAM).

(C) 2017 Universidad Nacional Autónoma de México, Facultad de Medicina, División de Estudios de Posgrado. Este es un artículo Open Access bajo la licencia CC BY-NCND (http://creativecommons.org/ licenses/by-nc-nd/4.0/). 
dría ir y venir de uno a otro, de acuerdo con el mismo proceso de la enfermedad y de sus necesidades.

Para asegurar continuidad en la atención, es esencial contar con cuidados paliativos en todos los niveles, son los sistemas de referencia y contrarreferencia los que acompańan al paciente en todo el proceso de enfermedad. Los pacientes con un adecuado control de síntomas y sin complicaciones, podrán ser atendidos en el primer nivel; aquellos en situaciones que requieren intervención instrumentada o de especialistas y los que no cuenten con infraestructura o una red de apoyo adecuada, deberán ser atendidos en el segundo y tercer nivel de atención.

En la atención primaria los tratamientos curativos y paliativos pueden y deben ocurrir simultáneamente durante el transcurso de la enfermedad. Sus beneficios son mayores si los ofrecemos desde etapas tempranas, incluso desde el diagnóstico, en el que pueden concurrir con tratamientos con fines curativos, a modo de cuidados de soporte, con lo que pueden atenuarse síntomas que aparecen como consecuencia de la misma enfermedad o su tratamiento, así como de condiciones comórbidas. Debemos hacer esfuerzos por intervenir a los pacientes de forma oportuna, conocerlo desde el comienzo de su enfermedad y los síntomas que lo aquejan, mejora la atención y disminuye la complejidad en las etapas más avanzadas.

En el pasado, únicamente los pacientes con un pronóstico de seis meses o menos de vida eran considerados como candidatos a cuidados paliativos; la tendencia internacional actual, ha modificado criterios para concentrarse, no solo en el pronóstico temporal de vida, sino en las características clínicas de los pacientes, sus padecimientos y circunstancias individuales.

Las instituciones de tercer nivel no tienen la capacidad para atender a todos aquellos pacientes con enfermedades crónico-degenerativas o con enfermedades limitantes o amenazantes para la vida. Para asegurar la cobertura universal en un país tan heterogéneo como México, se requiere de estrategias cuya visión consista en potencializar la atención primaria, con buena capacidad para atender a la mayor parte de los pacientes. Una atención primaria efectiva produce, además de beneficios y satisfacción al paciente y la familia, ahorros monetarios importantes, puesto que disminuye la necesidad de referir pacientes a unidades especializadas así como la admisión hospitalaria. Los beneficios no se limitan al manejo de síntomas físicos del paciente, sino que la atención paliativa ofrece apoyo, asesoría y acompańamiento para el manejo y el alivio de los aspectos psicoafectivos, espirituales y sociales que afectan, tanto al paciente como a sus seres queridos. Los pacientes atendidos desde el primer nivel pasan menos tiempo en unidades de cuidados intensivos, tienen menos ingresos hospitalarios, un mejor control de síntomas, sufren menos dolor, presentan menos problemas para respirar, muestran disminución en niveles de depresión y reportan mejor calidad de vida. Lo anterior, como se mencionó previamente, produce una mayor satisfacción en el paciente y su núcleo familiar, e incluso, en el personal de salud, ya que la atención se ajusta a los valores, metas y preferencias del paciente.

Para que se fortalezca la atención primaria y logremos el cometido dispuesto por la OMs, debemos fomentar la formación de equipos de atención primaria que proporcionen asistencia en casa, estos brindan información, alivio sintomático, soporte emocional y ayuda para mejorar la comunicación. Requerimos de un ejército para atender al grueso de la población, garantizar mayor cobertura y evitar embudos en los que los pacientes tengan que ser atendidos en los terceros niveles. Es preciso documentar la experiencia, a fin de fortalecer y optimizar recursos, talento e infraestructura que beneficie al paciente y su familia. Se trata de acompańar a los pacientes, a sus cuidadores y familias para tener claridad en la información que se les brinda, así como en las opciones y expectativas sobre su padecimiento. Lo anterior hará más sencillo el proceso de enfermedad y la toma de decisiones.

\section{Referencia}

1. Organización Mundial de la Salud. Global Atlas of Palliative Care at the End of Life. OMs; 2014. 